\title{
2 \\ Marco conceptual para una política cultural en el Perú
}

\section{Luis Repetto}

La realidad del Perú, amplia, diversa, rica y compleja, refleja el proceso histórico así como la estructura social y política de nuestro país. En ese sentido, la tarea de formular las pautas para un marco conceptual de la política cultural del Perú no sólo se hace ardua y difícil, sino que nos obliga de manera especial a tener presente el mosaico cultural que es el Perú, en donde todos los elementos se sustentan entre sí $y$ en el que no sería posible privilegiar a uno en detrimento de otro.

Con una antigüedad que supera los tiempos relativamente recientes de la presencia española, pero asumiendo la raíz de nuestra cultura en la amplia base indígena que ella tiene, no podemos dejar de reconocer el aporte fundamental de otros pueblos que han contribuido con elementos, de mayor o menos originalidad y calidad, en los últimos 500 años. Los pueblos, grupos, etnias, sociedades y regiones, se relacionan entre sí, con la naturaleza y con la formalidad del Estado de manera singular y propia. Ello genera expresiones culturales diversas y todas ellas, las urbanas y las rurales, las andinas, las selváticas y las costeñas, forman parte de este crisol extraordinario y singular que es el Perú, rico en matices y en manifestaciones culturales, en las que el mestizaje y el sincretismo se dan de la mano y van generando manifestaciones nuevas pero plenas en sí mismas. A ello sumamos, como es evidente, la riqueza de la naturaleza, el paisaje natural y la extraordinaria biodiversidad que posee nuestro país.

Por lo anterior podemos señalar que, para que la formulación que pretendemos tenga validez y credibilidad y pueda ser puesta en práctica, debe sustentarse en el conocimiento real y desprejudiciado de la sociedad y en el respeto a todas las formas de expresión cultural que se generan a partir de la creación natural y propia de nuestros pueblos. Estas pautas han de servir para orientar la acción normativa y rectora de una autoridad que se enfrentan al gran hacedor de cultura que es la sociedad misma. La nuestra será una labor de definición de liderazgo, de acción y de coordinación. Todos debemos entender que la riqueza cultural del Perú tiene que ser vista con ojos de unidad en la diferencia, con ojos de cuidado y protección por ser un bien frágil y no renovable y con respeto por ser uno de los pocos elementos en los que todos nos vemos reflejados. El desarrollo de un marco 
conceptual para la cultura en nuestro país debe tener como punto de partida la pluriculturalidad como característica principal de nuestro desarrollo histórico. Son más de 20 mil años de existencia de hombres y mujeres que dieron inicio a la creación de cultura. La cultura es la manifestación de formas de concebir la vida y la muerte. Estas manifestaciones culturales se dan a partir de la reproducción de condiciones para garantizar la vida, conviviendo y transformando los recursos del espacio geográfico, produciendo formas de comunicación como el lenguaje, los símbolos que permiten la organización social y política, la normatividad y el establecimiento de deberes, derechos, sistemas éticos y religiosos.

Nuestra historia está llena de acontecimientos que produjeron rupturas, marginación de procesos culturales, también formas particulares de sincretismo, de integración y de respuestas desde la gran diversidad cultural al desarrollo de políticas oficiales que a partir del siglo XVI con la conquista española y el inicio de nuestra relación con la cultura occidental se lograron desarrollar. A partir de la dominación colonial, la cultura occidental pretendió imponerse como la única que contenía verdades universales, considerando a las manifestaciones de los grupos que conformaron la extraordinaria civilización andina como carentes de cultura. Así aparece la noción de culto e inculto que está referida a este contexto, donde lo culto es 10 occidental y lo inculto o la ignorancia lo no occidental. Fueron cientos de años de vida colonial y luego republicana que consideraron a la política cultural oficial como la expansión de la cultura occidental que debía lograr su homogeneización y la transformación de las manifestaciones culturales andinas. La población andina, con sus expresiones étnicas y lingüísticas en sus distintos quechuas diferenciados por regiones y aymaras, así como los 53 grupos etnolingüísticos de la Amazonia, han integrado, reproducido, recreado en menor o mayor medida aspectos de la cultura occidental que finalmente les va permitiendo ganar espacios de expresión dentro de la sociedad nacional.

Los procesos de migración a la urbe obligan a la población rural a una nueva forma de vida. Esto produce una relación intercultural y reproduce nuevas manifestaciones de nuestra cultura. Teniendo en cuenta lo anterior, deseamos formular las pautas que sirvan para que, a través del Instituto Nacional de Cultura, el Estado cumpla su tarea de preservar, amparar, garantizar, conservar, estimular y promover las diversas manifestaciones de la cultura peruana.

Nuestra finalidad será contribuir a la libre realización de todos los peruanos, afirmando el valor de cada manifestación cultural y encontrando, en la diversidad ya señalada, la plenitud de nuestra riqueza cultural y de nuestra existencia como país. La tarea de dirigir el ente rector de la cultura nacional y el deseo de formular las pautas que orientarán nuestra acción en ese sentido, nos debe llevar, además, a señalar que nos mueve una actitud profundamente humanista $y$ democrática y que tenemos la plena convicción de que el acceso a la educación y la cultura, es un derecho inalienable del pueblo peruano, único hacedor y dueño de sus manifestaciones y que la participación del Estado debe ser cuidadosa para que no interfiera con la libertad creadora de los hombres, pero, al mismo tiempo, debe ser enérgica y decidida para protegerla y defenderla, en la medida en que en ella, que es a veces frágil y casi etérea, reside y reposa el sustento de nuestra propia identidad.

La cultura no es estática, se va recreando y enriqueciendo con nuestras manifestaciones a partir de los procesos sociales que se viven en nuestro país. Para el desarrollo de la política pluricultural tenemos que reconciliarnos respetando la diversidad y abrirnos a un diálogo donde ser diferente a lo occidental no es ser inferior sino distinto. Las propias manifestaciones de fusión que hoy conocemos por ejemplo en la música o en las plásticas ya nos van presentando los resultados enriquecedores de este diálogo. En este proceso de revaloración de la diversidad tenemos que desarrollar una labor que no sólo traiga como consecuencia la promoción y difusión cultural, sino que haga de nuestra riqueza patrimonial una fuente generadora de ingresos que mejore las condiciones de vida de nuestra población. Reconocer las expresiones plásticas actuales, danzas, cantos, literatura, folclore y asumir el conjunto de la biodiversidad y de formas tecnológicas desarrolladas, aprender de lo que tenemos y de lo ya se sabe en nuestro país sobre la energía, cultivos y estrategias organizativas es también una reconciliación entre nosotros. 
En el actual contexto de globalización la pluriculturalidad significa afirmar y difundir to nuestro que va desde lo desarrollado por los primeros pobladores de estas tierras, hasta los elementos del mundo moderno que hoy ingresan y se convierten en manifestaciones culturales de nuestros jóvenes. Así, afirmar lo nuestro, revalorarlo, reconocerlo y respetarlo entre todos los peruanos contribuirá a la creación de una Cultura de Paz en nuestro pais, tan deseada por todos. Sólo a partir de este proceso podremos presentar ante el mundo una imagen de nosotros atractiva, verdaderamente cautivadora. Podremos recuperar y ampliar nuestro espacio en el mercado exterior, exportar cultura y crear así la moda peruana en base a saber vender nuestra cultura como la mejor forma de fomentar el turismo.

La acción que deseamos llevar adelante obliga a pensar con miras al ya presente siglo $X X I$, aportando los criterios de modernidad autogestionaria sin descuidar los valores del desarrollo sostenible. La cultura debe avanzar hermanada con el desarrollo pues, asumiendo lo que se ha expresado una y mil veces, es imposible asegurar el progreso de los hombres y sus sociedades, si no tomamos en consideración la dimensión cultural del desarrollo. Dicho en otras palabras, para asegurar el camino hacia el desarrollo, no se requiere tan sólo de materiales y técnicas; el aspecto espiritual y la base cultural son elementos sustantivos en toda propuesta de crecimiento y progreso para los pueblos.

Ya en 1982, en México, la Unesco sentencio: "Un número cada vez mayor de hombres y mujeres desea un mundo mejor. No sólo persigue la satisfacción de las necesidades fundamentales sino el desarrollo del ser humano, su bienestar y su posibilidad de convivencia solidaria con todos los pueblos. Su objetivo no es la producción, la ganancia o el consumo per se, sino su plena realización individual y colectiva y la preservación de la naturaleza....El hombre es el principio y el fin del desarrollo... La cultura trata por ello y ante todo de acrecentar el ser del hombre, que sea más antes de que posea más. Sin la realización en profundidad del potencial humano, individual y social, todo proyecto de desarrollo económico y productivo es vano. La cultura es una dimensión fundamental del desarrollo" y, entendemos el desarrollo como el proceso que nos permite mayor libertad para conseguir aquellas cosas que realmente nos importan, es decir, aquellas cosas que tenemos razón y derecho de valorar.

En el documento, Nuestra Diversidad Creativa, señala importantes criterios que es el caso mencionar, como por ejemplo, el establecer que, dentro del campo de los derechos humanos, es indispensable considerar los derechos culturales de los pueblos y establecer que el gran desafío de las políticas públicas, es lograr políticas culturales para el desarrollo humano que, acordes con los tiempos actuales, garanticen la existencia digna de las manifestaciones culturales y permitan, al mismo tiempo, enfrentar los desafíos del mundo informático y de la llamada "aldea global" a la que pareciera estar destinado el mundo de las próximas generaciones. Señala, por ejemplo, que si bien la modernidad técnica puede ser asumida como una bendición, puede también ser una maldición y que es necesario encontrar el justo equilibrio para que la individualidad creadora no sucumba ante la uniformidad de criterios, gustos $y$ requerimientos.

Es por todos conocido que la incapacidad de las soluciones meramente económicas o políticas para controlar las contradicciones sociales, las explosiones demográficas y la depredación ecológica han llevado a científicos y políticos a preguntarse por las bases culturales de la producción y del poder. Se acepta que el desarrollo no es sólo una cuestión referida a patrones y niveles materiales, sino también al significado del trabajo y la recreación, al sentido que las sociedades construyen, junto con su producción, en las canciones y las imágenes, en el consumo, la educación y la vida diaria. Luego, para estudiar el desarrollo y sus crisis hay que tomar en cuenta tanto lo que declaran las encuestas y las cifras, como el abierto misterio del arte.

En los últimos años, quizás en las dos últimas décadas, la redefinición del concepto de cultura ha facilitado su reubicación en el campo político. Al dejar de designar únicamente el rincón de los libros y las bellas artes, al concebir la cultura en un sentido más próximo a la acepción antropológica -como el conjunto de procesos donde se elabora la significación de las estructuras sociales, se la reproduce y transforma mediante operaciones simbólicas-, es posible 
verla como parte de la socialización de las clases y los grupos en la formación de las concepciones políticas y el estilo que la sociedad adopta en diferentes líneas de desarrollo.

La situación actual es bastante crítica pues se reducen los fondos públicos para la educación y para investigar y difundir los bienes culturales, los salarios se empobrecen y estrechan la capacidad de acceder al conocimiento y el arte. En el momento en que comprendemos el papel que la cultura puede cumplir en la democratización de la sociedad, estamos justamente en las peores condiciones para desarrollarla, redistribuirla, fomentar la expresión y el avance de los sectores populares. Por esto mismo, si pensamos que el trabajo cultural es necesario para enfrentar democráticamente las contradicciones del desarrollo como recurso, para cohesionar a cada nación o clase en torno de un proyecto comprendido y compartido, como lugar en el cual se exprese la participación crítica de diversos sectores y se renueve en consenso, la crisis de la cultura debe tratarse junto con la que se vive en la economía y la política.

Entenderemos como administración cultural, el conjunto de intervenciones realizadas por el Estado, las instituciones civiles y los grupos comunitarios organizados, a fin de orientar el desarrollo simbólico, satisfacer las necesidades culturales de la población y obtener consenso para un tipo de orden o de transformación social. Pero si estamos convencidos de la importancia de los derechos culturales y del papel que la democratización de los bienes simbólicos cumple en la democratización global de la sociedad, las demandas en este campo debieran ocupar un puesto central en las luchas políticas para lograr cambios estructurales. Puesto que no hay una cultura legítima, la política cultural no debe dedicarse a difundir sólo la hegemónica sino a promover el desarrollo de todas las que sean representativas de los grupos que componen una sociedad. Entendemos que la cultura no se reduce a lo discursivo o estético, debe buscar la acción colectiva a través de una participación organizada, autogestionaria, reuniendo las iniciativas más diversas. Intentaremos, por lo tanto, que los propios sujetos produzcan el arte y la cultura necesarios para resolver sus problemas, afirmar o renovar su identidad.
Hasta tiempos muy recientes, el Estado se ha dedicado, prioritaria o exclusivamente, a conservar el patrimonio tradicional y sostener las actividades artísticas cultas y folklóricas cuya baja rentabilidad en el mercado vuelve difícil su subsistencia. Con grandes esfuerzos se logró ensanchar el concepto elitista de cultura para incluir las formas artesanales del arte popular, música, literatura indígena, etc. Pero cuesta extender el área de competencia del poder público hacia las manifestaciones que no son cultas ni tradicionales. Los procesos culturales son espacios donde se construyen la unidad simbólica de cada nación y las diferencias entre clases, donde cada sociedad organiza la continuidad y rupturas entre su memoria y su presente. Pero la cultura es además el territorio donde los grupos sociales se proyectan hacia el futuro, donde elaboran práctica e imaginativamente sus conflictos de identidad y realizan compensatoriamente sus deseos.

Una buena gestión a favor de la cultura no será la que asume en forma exclusiva la organización del desarrollo cultural en relación con las necesidades utilitarias de las mayorías, condición indispensable para que sea democrática, sino que abarca también los movimientos de juego y experimentación, promueve las búsquedas conceptuales y creativas a través de las cuales cada sociedad se renueva. Adicionalmente, la acción que deseamos desarrollar, debe ser también una política del placer. Se nos dirá que el placer no puede ser objeto de políticas. Es seguro que tienen razón si piensan en la política como esa telaraña de organigramas, trámites y astucias para conquistar el poder: ésta es la que casi siempre encontramos. Pero quizás se le pueda pedir precisamente a la política que se ocupa de la cultura, que se contagie un poco de los individuos y los grupos que la generan y están interesados en ampliar para todos el horizonte de lo posible, donde podamos incluir desde la literatura y la poesía hasta la cinematografía y las artes populares. 